\title{
TEXTO ENCARNADO: A ESCRITA A PARTIR DO CORPO
}

Diana Alves de Souza Magalhães

Recebido em 30/06/2017

Aprovado em 08/10/2017 


\begin{abstract}
Esse artigo apresenta a trajetória de uma pesquisa corporal e prática, que tem como objeto o circo, ao corpo do texto de minha dissertação do mestrado. Um caminho do subjetivo ao objetivo. Utilizo como ponte para essas duas esferas o antipodismo, uma técnica milenar do circo, nascida na China, onde se realiza malabarismo com os pés, utilizando variados objetos, como a sombrinha chinesa. Quais textos nascem a partir da prática corporal de uma técnica objetiva, direcionada por jogos de improvisação? Esses fragmentos textuais podem ser nossos suportes na transcrição de uma prática sensível a um modelo marcado pela objetividade que é a pesquisa acadêmica.
\end{abstract}

Palavras-Chave: Escrita. Subjetivo. Circo.

\title{
Ponto DE Início
}

S

ou ser em construção, em processo, sem introdução. Entro de sola, sou assolada. E assim como devaneiam as memórias, deixo a pena me guiar, me escrever. Tenho grande dificuldade com inícios, talvez pelo fato de sempre existir algo antes e em continuidade, não exista um ponto zero, mas o a partir de.

Às vezes me encontro refletindo sobre a origem de alguma ideia que veio como pensamento, mas não tem fim minha busca. Assim são nossas memórias. Flutuam em nossa mente de maneira aleatória, como páginas de um livro, soltas e ao vento. Pego uma página e é sobre essa que escrevo. Agarro-me a ela, pois sei que se amanhã fizesse a escolha, a página seria outra, afinal, como diz Larrosa (2004) foi esse o tempo que me tocou pensar, que me tocou escrever.

Hoje sou mãe de um menino de três anos. Até sua chegada, eu tinha controle, tinha domínio, sabia qual era o próximo movimento. Minha vida era segura e organizada. Mas ele chegou, e foi no parto que descobri que, dali para frente, tudo mudaria.

Ainda por dois anos, quis preservar áreas de minha vida, mesmo que pequenas, sem a intervenção dele. Uma delas era meu pequeno caderno artístico, sem pauta, onde escrevia de forma aleatória, porém organizada, pensamentos e registros de meus dias. Até que, sem pedir licença, ele veio e com uma caneta rabiscou minhas páginas sem linhas. Não tive forças para impedir, pois algo forte era lido em seus rabiscos. Sua vida ainda tão curta atravessaria toda a minha tentativa de manutenção da ordem e da segurança.

E assim surge a temática de minha pesquisa de mestrado. A ideia de uma criança que rabisca algo sistematizado e seguro, que não pensa, mas cria em um caderno aparentemente artístico, livre, mas cheio de normas e regras. A busca de um processo mais sensível na pesquisa de uma técnica puramente objetiva, que é o caso do circo. 
Percebi que se quisesse dar continuidade à minha atuação enquanto artista circense, não teria como fugir do tempo que agora me rodeia, com blocos de montar espalhados pela casa, com livros e cadernos rabiscados com canetinha, giz de cera. Seria injusto comigo, seria injusto com ele. E quem me legitima é Grotowski (2001): "de qualquer modo, a experiência da vida é a pergunta, enquanto a criação é, na verdade, simplesmente a resposta. Começa com o esforço de não se esconder e de não mentir" (Kolankiewicz apud GROTOWSKI, 2001, p. 7).

Formei-me em 2012 como técnica circense, pela Escola Nacional de $\mathrm{Circo}^{1}$, e, concomitantemente, como bacharel em interpretação pela Universidade Federal do Estado do Rio de Janeiro (Unirio). Nessa época o curso tinha duração de quatro anos. No primeiro ano o aluno era submetido a uma grade curricular única e básica: trapézio, arame fixo, acrobacias de solo e malabares. Depois deste ano podia escolher três modalidades, de acordo com seu interesse ou com suas habilidades corporais.

Em 2016 entrei no mestrado em Artes Cênicas da Universidade Federal de Uberlândia (UFU) com a seguinte proposta: Rabiscos verticais: $o$ uso da improvisação e da memória no ensino e pesquisa da arte do risco - o Circo, como uma tentativa de encontrar maneiras alternativas de ensino, e também da pesquisa pessoal do artista, sabendo do risco e da necessidade de o corpo ser preparado e trabalhado progressivamente para o aprendizado da técnica.

O universo do circo não é apenas o da ficção, ou o do ambiente lúdico para onde este nos transporta. Tem a ver também com um espaço e um tempo em que o corpo se move e se expressa de maneira totalmente distinta do habitual e, por isso, se torna um ótimo veículo para a improvisação e a descoberta de novas representações do mundo que nos cerca.

Para que isso ocorra, porém, o artista que faz uso da técnica circense tem de estar sensível para ser alguém além de um simples agente da exibição, e ser veículo portador de uma emoção consciente, como sugere Ritis (2009): "os tempos são finalmente maduros, sem dúvida, para que os técnicos e os intérpretes do circo possam ser os vetores de estados de alma" (RITIS, 2009, p. 136).

Somos infindos de possibilidades corporais, e o circo sempre esteve presente para nos lembrar disso, pois, nele o corpo se desenvolve para atingir limites maiores, ampliando o repertório de expressividades, mas o que se intitula como a grande vantagem, também se formula como o grande desafio. Trata-se de ir mais profundamente do que a forma e tentar produzir movimentos recheados de emoções e histórias pessoais, como sugere Zilé 
Muniz: "um corpo de memória que funciona no espaço da improvisação" (MUNIZ, 2014, p. 107).

Antes que me aventurasse em corpos alheios, por meio de experiências pedagógicas, eu precisava experimentar em um corpo já adestrado para o circo, e o que estava disponível e era de mais fácil acesso, era meu próprio. No entanto, no decorrer do processo do mestrado, me deparei com outra questão: como movimentar, a partir de minha pesquisa, quais partituras escrever na ação e como transcrevê-las sem perder o movimento e o ritmo? E a partir do suor da sala de ensaio, deixava que a mão deslizasse solta com caneta no papel e, depois, o trabalho na cadeira era apenas o de trazer conexões.

Segundo Baldi, "'caráter' designa 'a figura e o traçado da letra, que se chama elemento, feito com a pena sobre o papel"' (Baldi apud GINZBURG, 2007, p. 161). A elegância e a beleza dessa letra se assegurava a partir da agilidade de quem conduzia a pena. Os traços são únicos e carregam em si características e qualidades do condutor e talvez seja por isso o nome de caráter ou caractere. $\mathrm{O}$ escritor deixa rastros de si em sua escrita, assim como o bailarino, ator ou artista circense deixa um pouco dele em cena, rabiscando o espaço com seu corpo.

Talvez, mais intencionalmente do que outros, o bailarino responde ao mundo e às suas questões de forma corpórea, e por isso sua pesquisa atravessa seu corpo - este como plataforma, mas também como meio para produzir uma escritura, não só pela cena, mas também pela pesquisa, ora através da mão e ora pelo corpo, quando as palavras não possuem forças para definir ou explicar. Como diz Contreras (2013):

Existe un residuo de la experiencia que habita en nuestro cuerpo individual y también en nuestros cuerpos sociales que es irreductible a la palabra. Los saberes del cuerpo son otros tipos de conocimientos que pueden ampliar, airear, expandir los horizontes epistémicos a los que la academia eurocéntrica nos ha acostumbrado (CONTRERAS, 2013, p. 85).

E será isso, mesmo quando o corpo, em seu devaneio, necessitar sintetizar e registrar-se, na ordem das palavras, como borda o artista bispo do Rosário a frase tema de sua vida e obra: "Eu preciso destas palavras Escrita" (apud HIDALGO, 2009).

Por isso, a pesquisa em artes, algumas vezes, necessita visitar outros formatos de expressão para conseguir acompanhar aquele que conduz a pena, que realiza este movimento denominado Ductus; para "apropriar-se do mundo pela linguagem, aproximar-se das coisas, com o corpo, tê-las com o olhar e o pensamento" (FISCHER, 2005, p. 137), transitar neste corpo e, em uma batalha quase irreconciliável, trazer sentido e direcionamento a essa mão, esse corpo que insiste em deslizar e se rebelar da forma.

Além de refletir sobre como meu corpo alcançava determinada 
técnica do circo a partir do sensível, da improvisação, precisava pensar em como passar essa experiência para as letras no papel. Foi quando me matriculei na disciplina Tópicos especiais em Estudos do Corpo, oferecida pelo Programa de Pós-Graduação em Artes Cênicas da UFU, ministrada pela professora Renata Meira. A proposta curricular era vivenciar nossa pesquisa de mestrado através da improvisação, então, após alguns momentos de práticas corporais, tínhamos um tempo de escrita livre, e era a partir dessa que tecíamos nossa experiência no papel.

Registro a seguir partes dos textos escritos a partir da sala de aula e, muitas vezes, na própria sala. As aulas aconteciam em um espaço próprio para trabalhos corporais do curso de Teatro, e a professora direcionava alguns exercícios de improvisação a partir de estímulos visuais, imaginários e sonoros.

Foi pedido para que escolhêssemos um objeto, então, escolhi a sombrinha chinesa, para ter uma conexão com meu tema de pesquisa. Começava sempre com uma observação do corpo e sobre como este se apresentava no momento; depois era colocada uma música, selecionada para a aula, e, então, a professora apontava caminhos, a partir da fala, enquanto os alunos respondiam através do corpo.

Escrevo algumas notas de rodapé para que o leitor compreenda o que foi sugerido como estímulo. Para este artigo, porém, gostaria de ressaltar mais a escrita que nasce primeiro no corpo para depois ir para o papel.

\section{VISITA EXPERIMENTAL À PESQUISA}

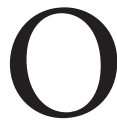
verbo se fez carne e habitou entre nós ${ }^{2}$. A palavra que outrora fora registrada em pedras, papiros, agora era verbo encarnado, a partir da pessoa de Jesus. Nossa pesquisa, muitas vezes destinada a morrer nas palavras aprisionadas em folhas, agora também seria palavra em ação, encarnada, corporificada e habitada finalmente em nós. Mas que tipo de texto sai de um processo de atravessamento corporal?

Se busco uma linha de pensamento, um cronograma dentro da pesquisa escrita, no corpo e na prática é diferente, não é linear. O corpo do texto é fragmentado, porque sem o corpo ele está incompleto. Escrevendo e atuando sobre memórias, me sinto como Sequeira (2010): “um alguém constelado de sensações quase lâmina, que lhe fustigam a alma e o forçam a ir anotando em páginas dispersas relevos existenciais se produzindo" (SEQUEIRA, 2010, p. 6). 
Dentro dessa visita experimental à minha pesquisa, escuto primeiro a minha voz, e me deixo ser achada por uma referência com a qual me delicio e em que encontro apoio para meus devaneios: as palavras da Preciosa Sequeira. E licenciada por ela, costuro uma nova roupagem em um tecido roto.

O que costuro é minha pele, é minha parte. Os dedos que trançam, corpo trançado, cabelo trançado, mente trançada são meus. Menina que se trança e tranca, corpo que se enrosca, texto que se tece, tecido entrelaçado, tapeceiro, tapete. Trança do corpo que vai para o cabelo, se trança. Corpo que trança, mente entrelaça. Texto tecido.

\section{EU ANIMAL ${ }^{3}$}

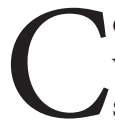

orpo circense, corpo sensível, que se esfrega, se sente, se arrasta, que vive. Que salta, que vai para o risco, que cai, se levanta, se arruma, se estende, tira a roupa, tira a pele, se suspende, se equilibra. Corpo que grita quem sou, que não entende, mas que se projeta, surpreende, se arrisca. Que risco! Chão, ar. Voa sem pé, sem apoio, alavanca. Tecido que prende, que se movimenta, se estica, cola no corpo, balança no ar. Cabelo que despenteia, sem técnica, cinto que amarra, se solta, machuca, arrasta, fricciona, cai e levanta, corpo que se fere, que se delicia, que experimenta, maneira, mente corpo que acompanha.

E deste corpo um animal se forma com características próprias, impostas pela imaginação. Se desenha a partir de medos, desafios, formatações já pesquisadas pelo corpo. Este meu ser em animal assume riscos, mas teme o risco, o voo do pássaro. É noturno e perturba o sono, mas na luz se esconde. Não gosta de água e também não é penetrado por ela, já que possui um casco grosso. Sente pelos dedos das mãos, vê com o pé. Se arrasta, mas salta, e no risco se recolhe, encolhe. Seu som vem do roçar de sua boca/presa. É agudo, curto, silencioso.

A cada encontro, cada aula, me deparo com este animal que me vem como parte do texto, carregando traço da prática, e este me esgota as energias, e assim canso, deito e apenas sinto. A cabeça pressionada, ora vê a luz, ora vê a sombra. Ela para baixo, quadril para cima, não se vê cadeira, mas se senta para pensar, refletir, reflexionar. Mente vazia volta-se para o corpo, onde flexões geram reflexões. Dedos tensionados, corpo tensionado, segura ar, solta o ar. 
De onde parto? Do ventre que nasce e se expande à extremidade? Cabeça quer pensar, corpo descansar. Quais as articulações que me estimulam? Estes que pressionam o pé no chão são os mesmos esmagados por ele, e que alavanca, me levanta do chão. Pé, mão, mão, pé, não sei quem suporta ou é suportado. E na arte do risco (circo) eles se confundem, trocam de funções, assim como o animal penetrado hoje em mim.

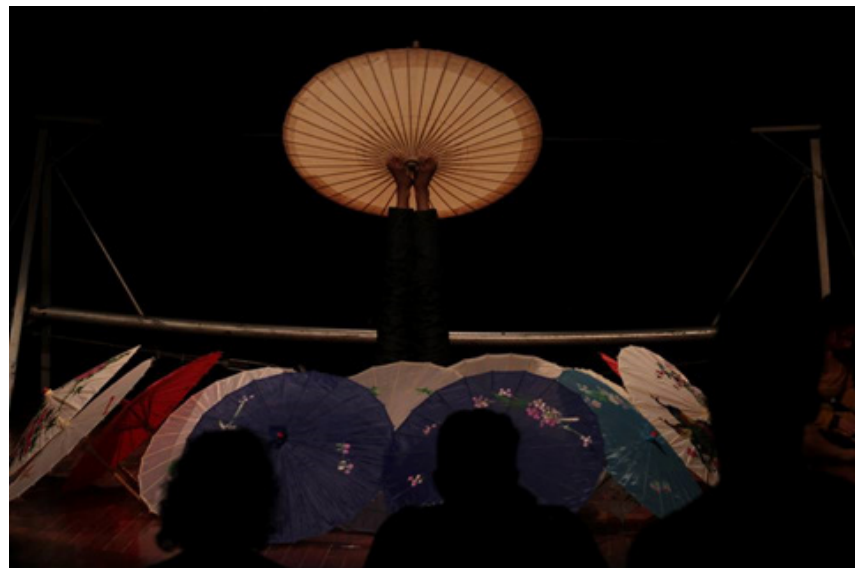

Figura 1: Sombrinhas

Fonte: Doni Malta ${ }^{5}$

\begin{abstract}
T evo sombrinha, sombrinhas. Por precaução, por proteção. São elas que pesam e que dão volume, mas insisto em transportá-las. Chove, chove vento, desestabiliza, surpreende. Escondo-me, me encasulo, me teço em seu ventre. Protejo, sufoco, me perco e me isolo sob a sombra. Fecho, peso nas costas, carrego, canga na nuca. Movimento-o, trago ao colo que embala, balança, ginga, mecaniza, enraivece, cansa. Finco-o no chão, e já passou, tão rápido. Ainda ontem no ventre, hoje quase três ${ }^{6}$. Gira, sopro, sopra corpo, deixo levar, vento me carrega.
\end{abstract}


Abro a maior das sombrinhas, chuva de papel, escritos fragmentados. Jogada pelo vento, tento recolher folhas de um livro em pedaços e junto com o balanço do corpo em equilíbrio, para que faça sentido para mim aqueles fragmentos desordenados. Está fora de controle, estão soltos. "Que fluxos são esses que se intrometem no meu corpo e me arrastam para esses abismos de sentido, revolvendo o chão firme em que acreditava pisar? De onde eles vêm? Que risco é esse que preciso aceitar?" (SEQUEIRA, 2010, p. 3).

Mas a água que tanto me incomoda, e me aterroriza, toca como tapas em meu corpo. É essa que escorre entre os meus dedos, que me molha e me sente e surpreende. A mesma que se acumula nos olhos que desaba na face, que molha os pés, mas que seca com os cabelos. Que bate no peito como uma onda e que me joga de peito como criança que escorrega. Ela que se infiltra entre os pisos que penetra. Deixa que venha, deixe que estrague, deixe que solte os azulejos da massa mal colocada. Deixe que venha como gota, deixe que venha como enxurrada, mas que venha. E que incomode, e que me solte, que me canse e me leve ao descanso, mas que venha!

\section{Eu CASA}

"Portando apenas uma leve bagagem de mão, deixou para trás um rosto, uma biografia, uma rede de relações familiares” (SEQUEIRA, 2010, p. 7).

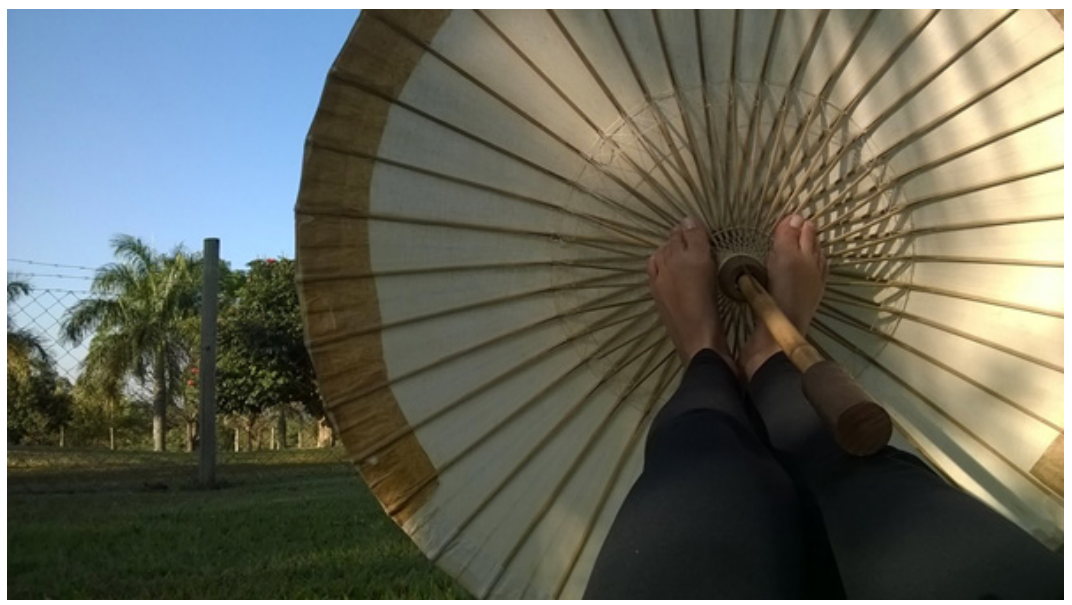

Figura 2: Varanda.

Fonte: Autora ${ }^{8}$ 
$\mathrm{U}$

m caminho até minha casa. Inicialmente solitário, só com borrões e sombras que percorrem também o seu próprio traçado. Nesse trajeto crio imagens, texturas, obstáculos, até chegar à varanda. É o mesmo a cada dia, porém, perspectivas diferentes me movem e levam meu corpo por outras vias.

Mas de onde parto? Onde inicia meu caminho e onde pretendo chegar? A pesquisa nasce de um desejo, e este não é concreto, não tem raiz visível e, longe do previsto, também não se sabe ao certo, só se supõe o resultado.

Até que chega o dia em que o encontro se torna, na carne, não metafórico e, então, uma sala cheia de obstáculos, ou seriam plataformas? Rachaduras ou brechas? De longe avisto minha meta. Em diagonal traço um caminho, mas ao ampliar a vista, vejo corpos. Ou seriam objetos? Sigo em frente, me enlaçam para trás. Passo em cima, sou apoio. Traz vida, mostra corpo. E agora não é mais um caminho com pedras imaginárias, mas corpos reais. Chego, enfim, em frente à porta. Mesmos movimentos, agora não tão cheios de sentidos, sentimentos, pois o que ficou e me moveu no entre os corpos que atravessaram e que me tocaram, é que me faz falta, é que traz corpo ao texto.

"Casa alguma aguarda seu retorno" (SEQUEIRA, 2010, p. 13), mas essa me aguarda, sempre está ali, pronta para me receber. Sou eu quem, na correria, me perco. E falo dela, da casa física, de minha morada, da casa família, de minhas relações, da casa eu, sempre em reforma, e dela, onde acolho todas essas outras, em palavras, ações, danças, minha pesquisa. Mas quando chego à porta de qualquer uma delas, quando penso em entrar, meu corpo - digo carne, digo mente, digo espírito, digo ser - tem medo, receio, se retrai, se esvai.

\section{Chave no tapete}

Varanda Ideal

Entro e descanso? 


\title{
CONCLUSÃO SEM PONTO
}

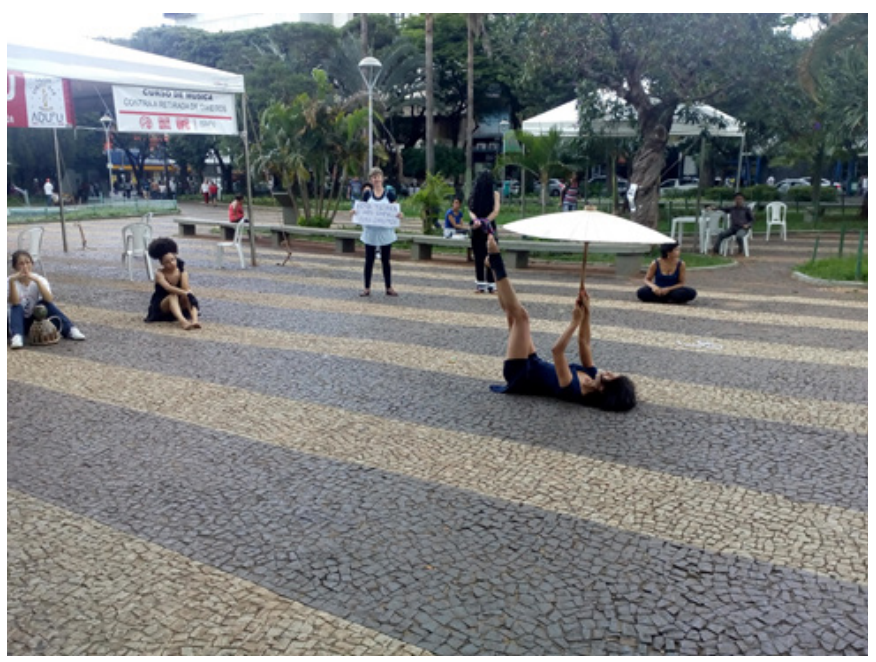

Figura 3: Caminhos

Fonte: Renata Meira ${ }^{9}$

\begin{abstract}
em combinar, sem planejar, saímos todos com suas bagagens ainda desarrumadas, e chegamos ali, no coração da cidade. Abrimos naquela praça, projetos disformes e, como um tapete de fios, trançamos sem nexo ou estrutura, sem compromisso com o discurso. Simplesmente compartilhamos nossas inquietações, a fim de encontrar outras inquietas mentes. Saio talvez mais confusa, mas quem disse que para ser interessante precisa ser linear?

Escrever com minha carne, com o que há de vivo em mim, meu material orgânico, tem sido um risco que decidi enfrentar. Ser habitada pelo objeto que pesquiso. E sendo habitada eu não crio, abro canais para forças criadoras perpassarem em mim. Por isso preciso me conectar a elas, revisitar minhas crenças, rituais, memórias e, a partir disso, escrever uma nova página. Sei sobre essa possibilidade do uso da intuição e da percepção como um método de escrita na pesquisa em artes, porém, também reconheço que devo buscar um rigor nas relações que estabeleço como fonte. Há uma necessidade de cuidado diário no processo, uma limpeza mental para não cair no engano de minhas emoções.
\end{abstract}


"Devemos lembrar de preencher a forma com vida. E isso requer prática” (GOLDBERG, 2008, p. 147). E essa prática da escrita independe de sua esfera de origem, seja ela corporal ou manuscrita. Nessa vivência, percebi que ora meu corpo era conduzido por algo sobre o qual eu já tinha refletido e escrito, ora minha mão era levada a escrever sensações transpiradas pelo corpo.

É uma escrita com o ritmo acelerado da prática, feita de imagens, texturas, e estava mais no material do que no campo das ideias. Não tem uma linearidade, mas é carregada de sentidos. Uma escrita que é preciso ser analisada na perspectiva de um sonho e não de um fato real. Não são formadas orações, mas quadros imagéticos pintados. E, apesar de ser mais subjetiva e cheia de traços pessoais, essa forma de registrar processo foi o mais próximo que conseguira chegar da prática. Não tem a ver apenas com minhas memórias, mas tem a ver com uma escrita que tento encontrar para acessar as minhas questões enquanto artista e pesquisadora.

E nesse caminho com outros colegas, percebi também que minha pesquisa não é o centro, não interessa mais do que a pergunta que move o outro. A única diferença é que ela habita em mim, mas é um fragmento, uma folha ao vento, e essa foi minha conclusão ao ver pesquisas diversas em corpos distintos. Por isso, a mim não importa pôr um ponto final, pois não tem a ver comigo, tem a ver com o que me move e para onde o vento me leva. E nessa perspectiva, encerro com as palavras de Sequeira:

Pode parecer estranho falar do poema, contêiner de acontecimentos, sem fazer menção alguma ao poeta que o escreve. É que interessa bem menos seu nome do que o fluxo de vida inventiva que o contagia e o mobiliza a traçar espaços menos homogêneos, menos modelares, mais imperfeitos, incompletos, imprevisíveis (SEQUEIRA, 2010, p. 18-19). 


\section{REFERÊNCIAS}

BÍBLIA sagrada: Revista e atualizada. Tradução de João Ferreira de Almeida. $2^{a}$ ed. São Paulo: Sociedade Bíblica do Brasil, 1993.

CONTRERAS, María José Lorenzini. La prática como investigación: Nuevas Metodologías para la academia Latinoamerica. Poiésis, n. 21-22, pp.71-86, jul.- dez. 2013.

FISCHER, Rosa Maria Bueno. Escrita acadêmica: arte de assinar o que se lê. In: Caminhos investigativos III. Organização de Maria Isabel Edelweiss Bujes; Marisa Vorraber Costa. Lamparina editora: Rio de Janeiro, 2005.

GINZBURG, Carlo. Mitos, emblemas, sinais. São Paulo: Cia das letras, 2007.

GOLDBERG, Natalie. Escrevendo com a alma: Liberte o escritor que há em você.Tradução Camila Lopes Campolino; revisão da tradução Silvana Vieira. São Paulo: Editora WMF Martins fontes, 2008

GOUDARD, Philippe. Estética do risco: do corpo sacrificado ao corpo abandonado. In: WALLON, Emmanuel (org.). $\mathbf{O}$ circo no risco da arte. Tradução de Ana Alvarenga, Augustin de Tugny e Cristiane Lage. Belo Horizonte: Autêntica Editora, 2009. P. 133-140 p. 25-31.

GROTOWISKI, Jerzy. Resposta a Stanislaviski. Tradução de Ricardo Gomes. Folhetim, n.9, jan-abr de 2001.

HIDALGO, Luciana. As artes de Arthur bispo de Rosário. Scientific American. Mente Cérebro: Psicologia,/ psicanálise/ Neurociência. Set/ 2009. Disponível em: http://www2.uol.com.br/vivermente/artigos/as artes de arthur bispo do rosario.html Acesso em: 10 de out 2016.

LARROSA, Jorge. A operação ensaio: sobre o ensaiar e o ensaiarse no pensamento, e na escrita e na vida. Educação e realidade. N. 29, pp.27-23. Jan/jun 2004. Disponível em: http:/www.seer.ufrgs.br/ educacaoerealidade/article/viewFile/25417/14743 >. Acesso em: 06 jun 2016.

MUNIZ, Zilá. Improvisação: descobrir camada por camada. Rascunhos - Caminhos da Pesquisa em Artes Cênicas: Dossiê Viewpoints: Estudos 
e Práticas. [online]. V.1, n.2, 2014 Uberlândia, IARTE/ GEAC/ EDUFU, [Aceso em 23 de setembro de 2015]. Disponível em $<$ http://www.seer. ufu.br/index.php/rascunhos/issue/view/1228 > jul/ dez 2014 p 93-112.

PROENÇA, Luana. Esconder e revelar: comentários sobre viewpoints, teatro e strip-tease. Rascunhos - Caminhos da Pesquisa em Artes Cênicas: Dossiê Viewpoints: Estudos e Práticas. [online]. V.1, n.2, 2014 Uberlândia, IARTE/ GEAC/ EDUFU, [Aceso em 23 de setembro de 2015]. Disponível em <http://www.seer.ufu.br/index.php/rascunhos/issue/ view/1228 $>$ jul/ dez 2014, p 28-36

RITIS, Raffaele. Ás origens da Mise em Piste. In: WALLON, Emmanuel (org.). O circo no risco da arte. Tradução de Ana Alvarenga, Augustin de Tugny e Cristiane Lage. Belo Horizonte: Autêntica Editora, 2009. P. 133-140

SEQUEIRA, Rosane P. Rumores discretos da subjetividade: sujeito e escritura em processo. Ed. Sulina, 2010. 